\title{
Use of Diazepam in Carotid Angiography
}

\author{
K. K. JAIN
}

SUMMARY Diazepam (Valium) has been used in 100 patients as a sedative for cerebral angiography. No serious complications were encountered. The advantages of this drug as well as the precautions for its use are listed.

RÉSUMÉ: Le Diazepam (Valium) fut administré à 100 patients comme sédatif en vue d'une angiographie cérébrale. Aucune complication majeure ne fut observée. Les avantages de ce médicament, ainsi que les précautions nécéssaires à son emploi sont répertoriés.
From the Department of Neurosurgery, Lions Gate Hospital, North Vancouver, B.C., Canada.

\section{INTRODUCTION:}

Diazepam (Valium "Roche") has been in general medical use since 1963. The oral form is used extensively in general practice for relief of anxiety and muscle spasms. Pharmacological data has been accumulated and it is generally considered to be safe with minimal side effects.

Intravenous diazepam has been used in neurology and neurosurgery since 1966 and has been found to be useful in controlling status epilepticus, (Wilson 1968). The author has used the drug for this purpose since 1967 and has found it to be safe and effective even in doses as high as 50 mgm. intravenously. Some patients went into a deep stupor following administration of high doses, but recovered promptly without any residual neurological changes.

Intravenous diazepam has also been used for anaesthesia, (Storner analgesia in combination with other agents. It was reported to be safe in various types of minor diagnostic and surgical procedures which have been performed by this method. However, there has been no report in the literature of cerebral angiography performed with the use of intravenous diazepam. For the past ten years the author has done the great majority of his cerebral angiography under local anaesthesia and has found it to be safer than general anaesthesia. In a et al, 1966) both for induction and personal series of over 1,000 consecutive angiograms there have been no major complications, morbidity, or mortality. The only defect of local anaesthesia was the pain experienced by the patient. To eliminate this, intravenous diazepam was tried in 1972 and over a period of one year, 100 consecutive angiograms were done using the drug in conjunction with other analgesics. Those patients who refused angiography under local, and those requiring surgery immediately following angiography were not included in this study.

\section{TECHNIQUE:}

Premedication for an adult is 60 mgm. of codeine or as an alternative $50 \mathrm{mgm}$. of meperidine (Demerol) combined with $50 \mathrm{mgm}$. of dimenhydrinate (Gravol) one half hour pre-operative. When the patient has been positioned on the X-ray table intravenous diazepam $10 \mathrm{mgm}$. is given by injection. If the patient is still restless a further $10-20 \mathrm{mgm}$. of diazepam is given intravenously. The maximum dose has not exceeded 50 mgm. in any patient. The effects last 15 to 30 minutes which is usually adequate to complete unilateral or bilateral procedures. After this the patient becomes restless and if the procedure is to be continued then direct intracarotid diazepam is injected. This has only been done recently after studying the report of Doppman (1973), who has shown that it is safe and effective.
TABLE 1

\begin{tabular}{lcc} 
Diagnosis & No. of Patients & No. of Angiograms \\
\hline Brain Tumor & 11 & 15 \\
Aneurysms \& Vascular Malformations & 15 & 42 \\
Traumatic Intracranial Hematomas & 19 & 23 \\
Cerebrovascular Occlusive Disease & 8 & 10 \\
Normal Findings* & 47 & 59 \\
Total: & 100 & 149
\end{tabular}

*Some of these patients subsequently were shown to have intracranial lesions which were demonstrated at pneumoencephalography. 
Most of the patients who were alert prior to angiography were drowsy but responsive to commands, and the motor power of the extremities could be tested during the procedure.

However, the patients have total amnesia for the procedure.

Table 1 is an analysis of 100 patients who underwent cerebral angiography and their diagnoses. Some of the patients had multiple angiograms, particularly those with intracranial aneurysms. These procedures were usually done at intervals of twenty-four hours and one patient required six injections to demonstrate an aneurysm. These injections were done over a period of one week. This would have been impossible under general anesthesia as the patient could not tolerate six anaesthetics in one week.

\section{NEUROLOGICAL OBSERVATIONS DURING ANGIOGRAPHY WITH \\ INTRAVENOUS DIAZEPAM:}

1. Patients without serious systemic disease and no pre-existing neurological signs showed only slight nystagmus, occasional slurred speech and ataxia, which were transient.

2. Patients with minimal neurological deficit such as hemiparesis showed accentuation of the deficit progressing to total hemiplegia, following injection of intravenous diazepam. This occurred most frequently with unilateral subdural hematoma where the hemiparesis was either minimal or not demonstrable. Also, patients with any space occupying lesions became more deeply comatose with a smaller dosage of diazepam compared to patients without a space occupying lesion. All accentuations of neurological deficits were transient. The patients recovered to their pre-angiogram status within a few hours.

3. Comatose and restless patients required variable doses to keep them immobile enough to complete the procedure. Alcoholic patients were particularly difficult and required variable amounts of intravenous diazepam. Some of the patients became hyper-exitable and had to be given unusually large doses of diazepam to calm them.

\section{COMPLICATIONS:}

The only complication was thrombophlebitis in one patient where diazepam was introduced into an already established intravenous with $5 \%$ dextrose solution. This complication has been reported by Langdon et. al, (1973) in $3.5 \%$ of 1,500 intravenous administrations of diazepam for gastrointestinal endoscopy. There were no respiratory or cardiovascular symptoms.

\section{PRECAUTIONS:}

This drug should not be used in patients with respiratory distress or cardiovascular collapse.

Also diazepam should be used cautiously or not at all in patients with liver or kidney disease. To prevent thrombo-phlebitis the drug should be injected directly into the vein as recommended by the manufacturers. Injectable diazepam has low solubility in water and other intravenous solutions and dilution leads to precipitation which causes irritation of the vein wall. Langdon et. al, (1973) have recommended avoidance of small veins and cautioned against giving diazepam in patients, with phlebitis or a history of phlebitis. They also suggest that if there is pain following the injection of diazepam the vein should be flushed with a solution of heparin and cortisone.

\section{REFERENCES}

DOPPMAN, JOHN L. (1973). Intra-arterial valium - its safety and effectiveness. Radiology: 106:335-338.

FRIEDENBERG, MAJ. WILLIAM. (1973). Intravenous diazepam administration. (Letter to the Editor) Journal of the American Medical Association: 224:901.

JUSKO, WILLIAM J. PLD. (1973). Precipitation of diazepam from intravenous preparations. (Letter to the Editor) Journal of the American Medical Association: 225:176.

LANGDON, COL. DAVID E. (1973). Thrombophebitis with diazepam used intravenously. Journal of the American Medical Association: 223: 184-185.

STOVNER, J. and ENDRESEN, R. (1965). Diazepam in intravenous anesthesia. Lancet 2: 1298-9. 18 Dec.

WILSON, PETER J. E. (1968). Treatment of status epilepticus in neurosurgical patients with diazepam (Valium). British Journal of Clinical Practice: 22:21-24. 